\title{
Study on How to Achieve 2030 Carbon Emission Peak in Power Sector
}

\author{
Lu Xing ${ }^{*}$ and Lu Cheng \\ State Grid Energy Research Institute, Beijing 102209, P.R. China \\ ${ }^{*}$ Corresponding author
}

\begin{abstract}
China made a commitment in Sino-US Joint Statement on Climate Change that its carbon emissions will achieve the peak around 2030, and the percentage of non-fossil energy in primary energy consumption will reach $20 \%$ then. This paper aimed to analyze the how the targets could be achieved by the transition of energy and power sector development. Studies show that the essential pathway to realize the 2030 targets is to control the total energy consumption and expand the use of clean energy to replace fossil energy. To achieve the target, China's non-fossil energy power installation and electricity generation should account for $47 \%$ and $37 \%$ of the national total respectively in 2030, and about $1 / 3$ non-fossil energy electricity needs to be transported through trans-regional power grid for utilization.
\end{abstract}

Keywords- carbon emission peak; energy; power sector; impact; clean energy

\section{INTRODUCTION}

In Sino-US Joint Statement on Climate Change, China made a commitment that around 2030 its $\mathrm{CO} 2$ emissions would reach the peak and the percentage of non-fossil energy in primary energy consumption would rise to about $20 \%$ in $2020^{[1]}$. Statistics suggests that energy-related $\mathrm{CO} 2$ emissions account for $70 \%$ of the total emissions ${ }^{[2]}$, which are the main source of carbon emissions. This objective puts a rigid restriction for the development of low-carbon energy. In combination with related research and analysis, this paper is dedicated to a quantitative study on the intrinsic requirement of this objective and its impact on the development of energy and electricity, and corresponding recommendations are proposed as well.

\section{INTRINSIC REQUIREMENT FOR PEAK CARBON EMISSIONS BY 2030}

A period in the future remains an important stage for our economic restructuring and we should address problems such as industrialization, urbanization, population growth and energy restructuring, etc. during development. The time and level of carbon emission peak are determined mainly by our choice of development mode.

Qimin Chai from the National Center for Climate Change Strategies ${ }^{[3]}$ believes that China still needs to address $20 \%$ industrialization, 20\% urbanization, 20\% energy restructuring and 20 years' gap of regional development. If China will have been basically industrialized by 2020 , the carbon emissions from industrial sectors will increase by over $1.2 \mathrm{~b}$ tons from 2015 to 2030 and industrial carbon emissions will peak on
$6.7 \mathrm{~b}$ tons. To achieve the estimated urbanization rate of 68 $72 \%$ by 2030 , the carbon emissions from new buildings and vehicles will increase 200 million tons annually. If we continue the traditional development mode, driven by industrialization and urbanization, China's carbon emissions will peak on at least 12.4 billion tons in 2030 .

The Green Book on Climate Change co-authored by Chinese Academy of Social Sciences and the National Weather Service ${ }^{[4]}$ points out that our industrialization and urbanization will be basically achieved in at least 20 years and the carbon emissions will peak between 2025 and 2040 in which the emissions from industrial sectors will peak between 2025 and 2030, maintain the value after peaking and begin to decrease around 2040. The urbanization rate will reach $70 \%$ around 2030 when China's per capita carbon emissions will possibly peak. According to the ceiling of emission reduction that China proposed, China's emissions will peak around 2025 with total emissions of 10.6 billion tons.

Boqiang Lin from Chinese Research Center of Energy Economics, Xiamen University ${ }^{[5-6]}$ believes that China's peak of carbon emissions is based on the peak of coal consumption. According to the current strength of smog treatment, China's coal consumption will peak in 2023 with a total consumption of $4.5 \mathrm{~b}$ tons. $\mathrm{CO}_{2}$ emissions will peak on 13 billion tons accordingly in 2028. Nevertheless, thorough stricter treatment, the coal consumption and $\mathrm{CO}_{2}$ emissions are likely to peak in 2020 and 2024 respectively on 4.2 billion and 11.7 billion tons.

The study of the State Grid Energy Research Institute ${ }^{[7,8]}$ suggests that in view of industrialization, urbanization, treatment of air pollution and coordinated development between eastern, middle and western areas, China will support its economic growth by a lower total energy consumption and a clearer energy consumption structure. In 2030, the total consumption of primary energy will reach 5.1-5.9 billion tons of standard coal under control in which coal accounts for 45$48 \%$. Around its peak in 2020 , the peak coal consumption will not exceed 4.1 billion tons. Non-fossil energy accounts for 23$25 \%$ of primary energy consumption and when the carbon emissions peak in 2030, its total emissions will be 10-11 billion tons. In the context of low-carbon emissions, the emissions are possible to peak around 2025 on about 10 billion tons.

To sum up, estimating according to the requirement of $2^{\circ} \mathrm{C}$ increase in temperature, China's peak carbon emissions should be controlled under 11 billion tons. This objective may force 
the total energy consumption to stand at 5.5-6 billion tons. With a decrease of coal percentage to $50 \%$ and an increase of non-fossil energy and natural gas to $20 \%$ and $10 \%$ respectively, the carbon emissions from energy activities can be controlled at $10-11$ billion tons. In the process, a key to bring carbon emissions to the peak earlier and lower is to control the total energy consumption. The estimate indicates that the total energy consumption in 2030 should be controlled at 5.5 billion tons of standard coal. Another key is to develop clean energy. Compared with such high-carbon energy as coal and fossil oil, electricity features outstanding carbon advantages: on one hand, compared with the utilization of coal and fossil oil, electricity generation enjoys a higher use efficiency. For example, coal-fired power generation is more efficient than coal firing. And electricity can meet the energy use demand of socioeconomic development more effectively. On the other hand, it can reduce the carbon emission intensity of electricity by increasing the percentages of zero-carbon energy such as nuclear and renewable energy in the electricity generation structure. But the carbon emission intensity of fossil energy is fixed and irreducible. To minimize carbon emissions, we should increase the percentage of clean electricity in installed electricity capacity and generating capacity as much as possible ${ }^{[9-12]}$.

\section{ANALYSIS OF ELECTRICITY DEVELOPMENT PLAN TO ACHIEVE PEAK CARBON EMISSIONS}

According to the above-mentioned analysis, the percentage of non-fossil energy in the consumption of primary consumption should reach $20 \%$ in response to the peak carbon emissions in 2030. Based on the figure, the total consumption of non-fossil energy should be 1.1 billion tons of standard coal, equivalent to an electricity production of $3600 \mathrm{TWh}$. On the basis of related analysis, the development of coal-fired electricity should peak before 2030 with a ceiling of $1200 \mathrm{GW}$ ${ }^{[13]}$. The exploitation sizes of hydro-power, nuclear power, wind power and solar power should be $400-480 \mathrm{GW}, 100-150$ $\mathrm{GW}, 300-500 \mathrm{GW}$ and $300-400 \mathrm{GW}$ respectively ${ }^{[14-16]}$. With the restrictions of the said non-fossil energy generation and installed capacity, this paper is dedicated to a benchmark plan for electricity development in 2030 as follows based on the optimization planning of power sources and the simulation and analysis of production.

\section{A. Analysis of Changes in the Installed Electricity Capacity Structure}

From the perspective of structural changes of the installed capacity, between 2015 and 2030, the percentage of installed coal-fired electricity capacity will decrease from $62.7 \%$ in 2014 to $40.1 \%$ in 2030 , a decrease of 23 percentage points; the percentage of installed non-fossil energy electricity capacity will increase from $31.6 \%$ in 2014 to $49.5 \%$ in 2030 , an increase of 18 percentage points; by 2030, the installed capacity of non-fossil energy electricity will account for half of the total installed capacity, surpassing that of coal-fired electricity; the new installed capacity of non-fossil energy electricity will account for $2 / 3$ among the new installed capacity, which features improved storage structure driven by increases.

From the perspective of structural changes in generating capacity, the percentage of coal-fired generating capacity will decrease from $72.4 \%$ in 2014 to $54.3 \%$ in 2030 , a decrease of 18 percentage points; that of non-fossil energy will increase from $25.3 \%$ in 2014 to $39.2 \%$ in 2030 , an increase of 14 percentage points. The generating capacity of non-fossil energy accounts for more than a half $(57 \%)$.

TABLE I. THE STRUCTURE OF CHINA’S INSTALLED ELECTRICITY CAPACITY IN 2030

\begin{tabular}{|c|c|c|c|c|c|c|}
\hline \multirow{2}{*}{ Type } & \multicolumn{3}{|c|}{ States quo $2014^{[17]}$} & \multicolumn{3}{|c|}{ Projection 2030} \\
\hline & $\begin{array}{l}\text { Capacity } \\
(10 \mathrm{MW})\end{array}$ & $\begin{array}{l}\text { Generation } \\
(100 \mathrm{GWh})\end{array}$ & $\begin{array}{l}\text { Utilization hours } \\
\text { (h) }\end{array}$ & $\begin{array}{l}\text { Capacity } \\
(10 \mathrm{MW})\end{array}$ & $\begin{array}{l}\text { Generation } \\
\text { (100 GWh) }\end{array}$ & $\begin{array}{l}\text { Utilization hours } \\
\text { (h) }\end{array}$ \\
\hline Coal-fired power plant & 85128 & 40139 & 4715 & 115000 & 54050 & 4700 \\
\hline Gas plant & 5567 & 1183 & 2125 & 20000 & 6000 & 3000 \\
\hline Regular hydro power & 28000 & 10540 & 3764 & 43000 & 15050 & 3500 \\
\hline Nuclear power & 1988 & 1262 & 6348 & 13000 & 9360 & 7200 \\
\hline Wind power & 9581 & 1563 & 1631 & 43000 & 8170 & 1900 \\
\hline Solar power & 2428 & 231 & 951 & 40000 & 5200 & 1300 \\
\hline Biomass power & 920 & 420 & 4565 & 3000 & 1200 & 4000 \\
\hline Pumped storage & 2183 & 121 & 554 & 10000 & 500 & 500 \\
\hline Total & 135795 & 55459 & 4253 & 287000 & 99530 & 3470 \\
\hline
\end{tabular}




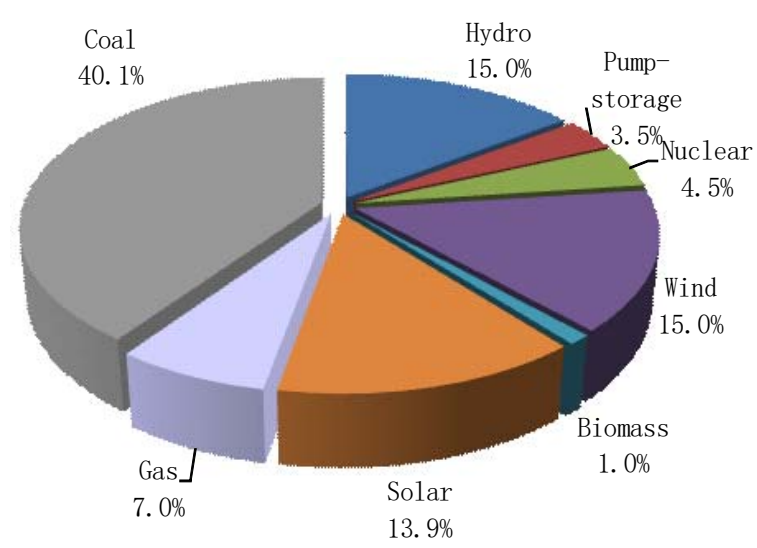

Power structure in $\mathbf{2 0 3 0}$

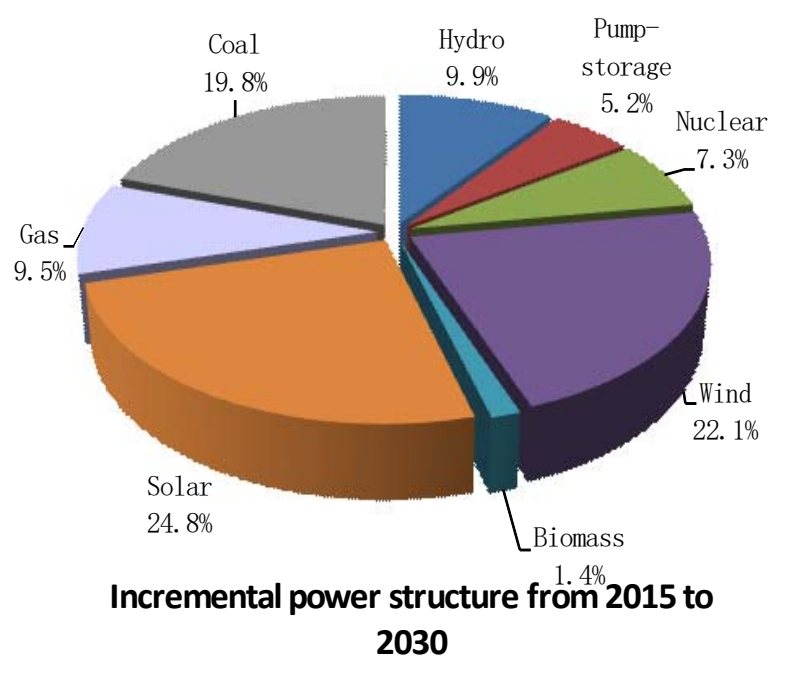

FIGURE I. THE STRUCTURES OF CHINA'S INSTALLED ELECTRICITY CAPACITY AND INCREASES IN 2030

\section{B. Analysis of Contributions Made by Various Non-Fossil Energy}

Based on the analysis in Fig 1, between 2015 and 2030, the installed capacity of hydro-electricity will increase by $150 \mathrm{GW}$ an annual increase approximate to $10 \mathrm{GW}$. The percentage of hydro-power will near $40 \%$ among the total electricity generation of non-fossil energy in 2030, which is the main power source to achieve the objective; as a result of optimization, the installed capacity of nuclear power will increase by $110 \mathrm{GW}$, an increase of about $7 \mathrm{GW}$. Its increased power production accounts for $32 \%$ in the total increased electricity of non-fossil energy, which is a predominant increase, essential to achieve the objective. The contribution of wind power will increase to $21 \%$, while that of biomass and solar electricity is lower, about $16 \%$.

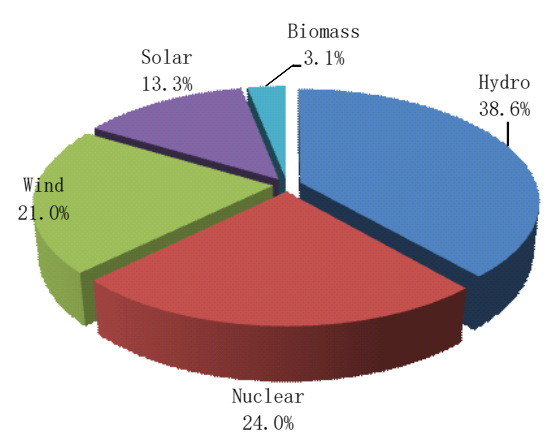

Non-fossil ectricity structure in 2030

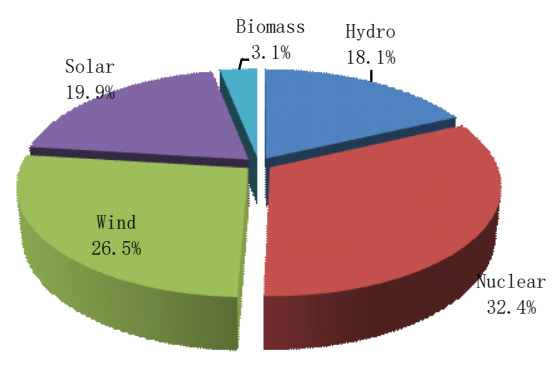

Non-fossil ectricity incremental structure from 2015 to 2030

FIGURE II. THE STRUCTURES OF CHINA'S NON-FOSSIL ENERGY GENERATING CAPACITY AND INCREASES IN 2030

\section{Analysis of Non-Fossil Energy Absorption Plan}

Based on the benchmark plan, hydro-power will increase by $150 \mathrm{GW}$ between 2015 and 2030 among which $90 \%$ is owed to the southeastern provinces: Sichuan, Yunnan and Tibet. Most of them need to be absorbed in middle and eastern areas, especially the hydro-power from Tibet. Balance analysis ${ }^{16}$ suggests that the total demand of trans-provincial hydro-power in 2030 will be $180 \mathrm{GW}$. The exploitation size of wind power in 2030 will be $430 \mathrm{GW}$ and to absorb them efficiently and reduce wind curtailment, we need to transmit $180 \mathrm{GW}$ out for absorption. The installed capacity of solar power will be $400 \mathrm{GW}$ more than half of which is owed to the large PV power stations in western areas and about $150 \mathrm{GW}$ PV power need to be transmitted out for absorption. Generally, $510 \mathrm{GW}$ clean electricity is absorbed by transmission to other areas thorough grid, accounting for about $40 \%$ of the total exploitation size. At present, about $70 \mathrm{GW}$ non-fossil energy electricity is absorbed by trans-provincial transmission. To achieve the objective in 2030, the transmission size of power grid should be enlarged as much as more than 6 times. We should make efforts to plan and regulate power sources and grid, accelerate the approval and construction of the transmission channels from large energy bases in western and northern areas and ensure that clean electricity can be both transmitted out and preserved locally so as to reduce wind, water and light curtailment and avoid the considerable waste of capital and resources.

Another measure to use non-fossil energy efficiently is to improve our ability of systematic adjustment. First, we should accelerate the construction of flexibly adjusted power sources 
like pumped storage; and second, we should improve the flexibility of power grid. Since usually nuclear power is not involved in systematic peak load regulation, in most cases, it features adverse effects against peak load regulation, but the non-fossil energy exploited on a large scale may increase the pressure of peak load regulation for the system. Based on the simulation and analysis of planning and production, between 2015 and 2030, China new installed capacity of pumped storage and gas-fired power stations will be $80 \mathrm{GW}$ and 140 GW respectively of which more than $80 \%$ is owed to middle and eastern areas ${ }^{[18]}$. We should strengthen our efforts in planning and practicing and policy support, ensuring that it can be put into production on time. On the other hand, we should strengthen our construction, operation and management of smart grid, establish a flexible pricing mechanism encouraging users to interact, and make more efforts to the R\&D and demo of advanced technology and key devices such as chemical storage so as to improve the intelligence of each grid component and its ability of receiving random power sources.

\section{Sensibility Analysis and Solutions}

At present, the planning of hydro-power watershed has been completed. There is a large size of large-scale hydropower bases under construction or planned to construct, which is very likely to reach $430 \mathrm{GW}$ by 2030 . Wind generation and PV generation enjoy a shorter construction cycle and it is basically under control to achieve the estimated installed capacity. In view of such factors as nuclear safety and inland nuclear power dispute, etc, there are uncertainties to achieve the $130 \mathrm{GW}$ installed capacity of nuclear power in 2030 . If the size of nuclear power put into production is $100 \mathrm{GW}$ only with a $30 \mathrm{GW}$ decrease, the generating capacity of non-fossil energy will decrease by 22 TWh accordingly. A substitute of such electricity requires more than $60 \mathrm{GW}$ hydro-power put into production and the total installed capacity of hydro-power need to reach about $500 \mathrm{GW}$. Since the hydro-power possible to be exploited is located mainly in Jinsha, Nujiang and Yajiang watersheds, difficult exploitation and long construction cycle make it impossible to increase in the short term. A substitute of such decreased electricity requires 120 $\mathrm{GW}$ more of wind power or $180 \mathrm{GW}$ more of solar power. The difficulty lies in the risks that renewable energy synchronization, transmission and absorption may bring to the control of the stability. A possible solution is to formulate active policy incentives, strengthen technological breakthrough in reforming end-use energy such as distributed energy and new energy storage. Moreover, we should activate the market of new energy generation such as indoor PV and transportation energy use, reduce end energy waste significantly while increasing the use of renewable energy on a large scale, ensuring that the ideal percentage of non-fossil energy will be achieved in 2030 .

\section{CONCLUSION}

In the future, with the increased percentage of clean electricity in China's installed capacity and generating capacity, electricity will feature more outstanding "carbon advantages" compared with other energy, as a key to ensure that our carbon emission will peak and the peak value will be lowered. We should make efforts to middle- and long-term electricity and grid planning in advance in accordance with the requirements of non-fossil energy exploitation and transmission, enabling clean electricity to play its part in energy supply. On the other hand, we should promote the large-scale application of distributed energy, enlarge the use scope of renewable and the low-carbon development of end energy use.

\section{REFERENCES}

[1] Chai, L. (2014). The Meaning of China's Carbon Emission Peak in 2030. [online] Available at: http://opinion.caixin.com/2014-1119/100752759.html

[2] Chen, X., Zhou, T., Li, X., et al., (2012). Structure Identification of CO2 Emission for Power System and Analysis of Its Low-carbon Contribution. Automation of Electric Power Systems, 36(2), pp. 18-25.

[3] China Electricity Council (2015). 2014 National Electricity Power Industry Statistics Express.

[4] Chinese Academy of Engineering (2011). China's Mid- (2030) and Long-term (2050) Energy Development Strategy Research. Beijing.

[5] He, Y., Ye, X., and Wang, Z., (2015). The Development Trend of Coal Industry and Outlook for "13th Five Year Plan". China Energy News.

[6] Huo, M., Han, X., and Shan, B., (2013). Empirical Study on Key Factors of Carbon Emission Intensity of Power Industry. Electric Power, 46(12), pp. 122-126.

[7] Huo, M., Xing, L., Shan, B., et al., (2014). Study on the Bottom-up Estimation Methodology of Carbon Mitigation of China's Power Sector. Electric Power, 47(11), pp. 155-160.

[8] International Panel on Climate Change (IPCC). (2007). IPCC Fourth Assessment Report: Climate Change 2007 (AR4). [online] Available at: http://www.ipcc.ch/report/ar4/

[9] Lin, B. (2014). Expert's Opinion on Realization Route for China's Carbon Emission Peak: Coordinating Energy, Environment and Economy. Outlook Weekly, Vol. 1604. Beijing.

[10] Lin, B. (2014). Carbon Emission Commitment to Force China's Environment Protection. Environment Education, Dec, 2014, pp. 16-17.

[11] National Energy Administration (2010). 2030 Scienfically-developing National Energy Strategy Research Report. Beijing.

[12] New China News Agency, (2014). U.S.-China Joint Announcement on Climate Change. [online] Available at: http://news.xinhuanet.com/energy/2014-11/13/c_127204771.html

[13] State Grid Energy Research Institute, (2014). An Analysis of Energy Demand of Eastern, Central and Western Regions and the Trend of Demand Change of West-East Electricity Transmission Project.

[14] State Grid Energy Research Institute and General Institute of Hydropower and Water Resource Planning and Design (2015). Clean Energy Base Exploitation and Delivery Research.

[15] State Grid Energy Research Institute (2015). Peaking Units' Expansion Planning Research in Accordance to Clean Energy Development.

[16] Tian, Z., Yang, Z., and Cai R., (2015). Study on Contribution of Power Industry for Regional Energy Conservation and Carbon Intensity Reduction Goal. Electric Power, 48 (3), pp. 150-155.

[17] Wang, W., Zheng, G. and Pan, J. (2014). Green Book of Climate Change: Annual Report on Actions to Address Climate Change. Beijing: Social Science Academic Press (China)

[18] Xu, M., Hu, Z., Tan, X., et al., (2012) .Scenario Analysis on Mid-long Term Energy, Electricity Demand and Carbon Emission in China. Electric Power, 45(4), pp. 101-104. 